condition is deteriorating and some pharyngea bleeding is known to have occurred. The anaesthetist's aching left arm and mounting sense of doom incline him to consider bronchospasm or tension pneumothorax as possible causes of his problem, reinforcing a subconscious reluctance to admit failure and remove the tube. If the tube is merely disconnected, an airway inserted alongside, and a mask placed over the lot, ventilation is usually easy, the patient's condition rapidly improves, and time is gained to reassess the situation relatively safely with the tube acting as a bung in the oesophagus. The speed and ease of this manoeuvre do not rule out the assembly and use of all the other excellent technical aids, but it combines diagnosis with treatment more or less instantly.

If you arrive on the scene as the second anaesthetist this procedure is much less aggressive to your unfortunate colleague and much safer than following the unhelpful, if attractive, maxim "when in doubt take it out." The method of ventilating patients without direct connection of the endotracheal tube must have been used quite often in the early days of modern anaesthesia since it is one of the options on the excellent anaesthetic record card designed by Dr Michael Nosworthy. Anaesthetists are often short of the necessary equipment: catheter mounts then, pulse oximeters and capnographs now.

M L HEATH

Lewisham Hospital,

London SE13 6LH

\section{Association between mortality among women and socioeconomic factors}

SIR,-_Unlike Dr Freda E Alexander and colleagues (26 September, $p$ 754), I have found no important correlation in my part of the world between smal area mortality and measures of socioeconomic state.

The figure shows the standardised mortality ratios for electoral wards in North East Essex district (1981 to 1984) plotted against the proportion of overcrowded houses $(>1.5$ people per room at census in 1981). Though a technically significan correlation exists (rank correlation coefficient $0 \cdot 26$,

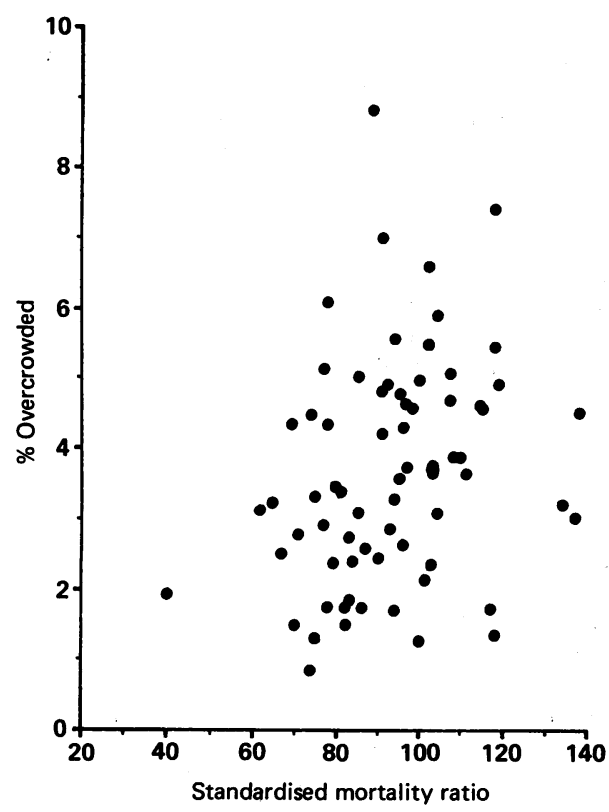

Standardised mortality ratios for electoral wards in North East Essex Health Authority 1981-4 in relation to proportion of overcrowded houses. $\mathrm{p}<0.5$ ), the relation between overcrowding and mortality is, for practical purposes, nil. Scattergrams for other measures, such as unemployment and mobility, and for a composite index show a similar picture.

The link between social deprivation and mortality, missing in north east Essex, is perhaps forged by the harsher climate, physical and economic, of Edinburgh.

E G JESSOP

North East Essex Health Authority, Essex CO4 5JR

\section{Very low birthweight survivors}

SIR,-The paper on low birthweight survivors by Dr H Skeoch and colleagues confirmed that these infants have increased morbidity in their early years (5 September, p 579). We had always suspected this to be the case as, apart from physical considerations related to the low birth weight, there are other factors to be considered, such as the increased anxiety of parents and even general practitioners. We also think that the figures should have been matched against controls from the same socioeconomic background, as this may well influence the number of admissions to hospital. Surely the socioeconomic background also affects the number of very low birthweight babies delivered.

The implication in the comment is that these very low birthweight children should not be expensively resuscitated because of $(a)$ financial and $(b)$ psychological considerations. The authors' order of priority is noteworthy. It would be interesting to know the long term outcome of these children, who are now around 4 years of age. We suspect that most will be developing normally when compared with their peers. If so, we wonder if the parents would take kindly to the suggestion that their psychological traumas should have taken priority over the preservation of the life of their child. Furthermore, we can only presume that this exercise was undertaken to establish the need for more/less government funding in a certain area.

At its most extreme it could be interpreted as a neat way of selectively reducing the population of lower socioeconomic groups, given our premise above. Are we being naive or just misunderstanding the point?

C JENKINS

Community Health Services Office, Powys SY16 2NG

\section{P M HAMADE}

AUTHORS' REPLY,-Drs Jenkins and Hamade correctly state that socioeconomic class influences both the incidence of low birth weight and the rate of hospital admission in infancy. ${ }^{12}$ There is, however, an independent effect of low birth weight on subsequent morbidity even when social factors are controlled for. ${ }^{3}$ Furthermore, in our small sample of 41 normally developed survivors of less than $1500 \mathrm{~g}$ birth weight 30 were from families where the head of the household was in employment and 28 were from owner occupied homes. When these figures are compared with 1981 census data for residents of the Greater Glasgow Health Board area ( $21 \%$ unemployed, $32 \%$ owner occupiers) there is no evidence of skewing of our sample towards disadvantaged social classes. Our control figure for the hospital admission rate for all children in Glasgow of $13.9 \%$ therefore remains appropriate. The positive association between subsequent morbidity and duration of assisted ventilation also indicates that we are observing consequences of events in the neonatal period rather than social factors, although these may well exacerbate the problems.

The length of short reports is limited so that our comments had to be terse. We certainly did no imply that these babies should not be resuscitated. Decisions about the weight and gestation at which intensive care should be started will be based on information allowing prediction of survival and probability of handicap or other forms of morbidity influencing the quality of life. Only through comprehensive long term follow up of representative samples of these babies will the information be available to paediatricians and parents to make informed decisions. This cohort of children is therefore being re-examined now by health visitors and a study is under way to follow up all babies who were born weighing less than $1750 \mathrm{~g}$ in 1984 in mainland Scotland.

Our reference to the psychological strains of looking after these often ill babies was to call attention to the need for better follow up support in the community.

H SKEOCH C SKEOCH

G MCILWAINE

K ROSENBERG T TURNER

Glasgow Royal Maternity Hospital,

Glasgow G4 ONA

1 Townsend $\mathbf{P}$, Davidson $\mathbf{N}$. Inequalities in health London: Penquin, 1982. (Black report.)

2 Gilchrist I, Rosenberg K. Hospital admission in the first year of life. Health Bulletin 1986;44:29-36.

3 McCormick M, Shapiro S, Starfield B. Rehospitalisation in the first year of life for high-risk survivors. Pediatrics 1980;66: $991-9$.

\section{Portraits from Memory}

SIR,-My appreciation of Sir James Howie's Portrait from Memory of Dr Eric Catford (10 October, p 901) was heightened by the graceful tribute it paid to the late P G Shute, one of the unsung heroes of scientific discovery. For many years I had the pleasure of meeting him for lunch in the medical officers' dining room at Horton Hospital, Epsom, and came to know him well as a man and as a friend.

Shute was much more than a "very superior laboratory technician and a real specialist in malaria." He was acknowledged as a world class scientist who by his own genius and hard work had heaved himself up to the position of assistant director of the prestigious Horton Malaria Laboratory, which he had joined as a lab boy in 1925 .

Sir James is obviously aware that the exoerythrocytic forms for human malaria parasites were found as Shute had predicted; but what he may not know-and I apologise if he does-is that this vitally important discovery was made as a direct result of work done in the Horton laboratory. A report was in fact published in the $B M \mathcal{F}$ shortly afterwards. ${ }^{1}$

Sir Gordon Covell, codirector of the Horton Laboratory, could not speak too highly of Shute's work. He told me on more than one occasion that had he had the right sort of academic background (his only formal training was as a baker) he would certainly have been elected FRS. And yet so modest and self effacing a man was he that should he have been so elected it would not, I am sure, have made the slightest difference to his demeanour.

Horton Hospital

HENRY R ROLLIN Epsom

Short HE, Garnham PCC, Covell G, Shute PG. The preerythrocytic stage of human malaria, Plasmodium vivax. $B r$ Med F 1948;i:547. 